\title{
Effect of reducing the paediatric stavudine dose by half: a physiologically-based pharmacokinetic model
}

Sherwin K.B. Sy ${ }^{a}$, Ruben Malmberg ${ }^{a}$, Aoi Matsushima ${ }^{a}$, Eduardo Asin-Prieto ${ }^{a}$, Bernd Rosenkranz ${ }^{b}$, Mark F. Cotton ${ }^{c}$, Hartmut Derendorf ${ }^{a, \star}$, Steve Innes ${ }^{c}$

a Department of Pharmaceutics, College of Pharmacy, University of Florida, Gainesville, $F L, U S A$

${ }^{\mathrm{b}}$ Department of Pharmacology, Stellenbosch University, Cape Town, South Africa

'Children's Infectious Diseases Clinical Research Unit, Tygerberg Children's Hospital and Stellenbosch University, Cape Town, South Africa

ARTICLE INFO

Article history:

Received 8 July 2014

Accepted 10 December 2014

Keywords:

Stavudine

Physiologically-based pharmacokinetics

Paediatric reduced dose

Advanced dissolution, absorption and metabolism (ADAM) model 
* Corresponding author. Tel.: +1 352273 7856; fax: +1 3522737855.

E-mail address: hartmut@cop.ufl.edu (H. Derendorf). 


\section{ABSTRACT}

Owing to significant dose-related toxicity, the adult stavudine dose was reduced in 2007. The paediatric dose, however, has not been reduced. Although the intended paediatric dose is $1 \mathrm{mg} / \mathrm{kg}$ twice daily (b.i.d.), the current weight-band dosing approach results in a mean actual dose of $1.23 \pm 0.47 \mathrm{mg} / \mathrm{kg}$. Both efficacy and mitochondrial toxicity depend on the concentration of the intracellular metabolite stavudine triphosphate (d4T-TP). We simulated the effect of reducing the paediatric dose to 0.5 $\mathrm{mg} / \mathrm{kg}$. A physiologically-based pharmacokinetic model consisting of 13 tissue compartments plus a full ADAM model was used to describe the elimination of stavudine. The volume of distribution at steady-state and apparent oral clearance were simulated and the resulting AUC profile was compared with literature data in adult and paediatric populations. A biochemical reaction model was utilised to simulate intracellular d4T-TP levels for both the standard and proposed reduced paediatric doses. Simulated and observed exposure after oral dosing showed adequate agreement. Mean steady-state d4T-TP for $1.23 \mathrm{mg} / \mathrm{kg}$ b.i.d. was $27.9(90 \% \mathrm{Cl} 27.0$ 28.9) fmol $/ 10^{6}$ cells, $25 \%$ higher than that achieved by the $40 \mathrm{mg}$ adult dose. The 0.5 $\mathrm{mg} / \mathrm{kg}$ dose resulted in d4T-TP of $13.2(12.7-13.7) \mathrm{fmol} / 10^{6}$ cells, slightly higher than the adult dose of $20 \mathrm{mg}$ b.i.d. [11.5 (11.2-11.9) fmol/ $10^{6} \mathrm{cells}$, which has excellent antiviral efficacy and substantially less toxicity. Current paediatric dosing may result in even higher d4T-TP than the original $40 \mathrm{mg}$ adult dose. Halving the paediatric dose would significantly reduce the risk of mitochondrial toxicity without compromising antiviral efficacy. 


\section{Introduction}

The current standard paediatric dose of stavudine is $1 \mathrm{mg} / \mathrm{kg}$ twice daily (b.i.d.); however, the current weight-band dosing approach results in a mean actual dose of $1.23 \pm 0.47 \mathrm{mg} / \mathrm{kg}$ b.i.d. At the current dose, stavudine is associated with progressive fat metabolism defects including lipoatrophy, lipohypertrophy, dyslipidaemia and insulin resistance. Lipoatrophy, a very slowly progressive disfiguring loss of fat in the face and limbs, may begin after as little as 6-9 months of therapy and eventually appears in up to $36 \%$ of children [1]. This stigmatising condition has become the hallmark of human immunodeficiency virus (HIV) infection and often leads to reduced adherence to antiretroviral therapy (ART). Lipohypertrophy, which involves abnormal fat accumulation in the breasts, abdomen and nape of the neck, is less common before puberty [2]. Dyslipidaemia and insulin resistance have both been associated with early atherosclerosis-like vascular abnormalities in children [3]. One option to manage toxicity is to switch to another antiretroviral medication, however for children in the developing world the options are limited. The anaemia-inducing effect of zidovudine limits its usefulness, especially in sub-Saharan Africa where malaria- and malnutrition-related anaemia is already common and is strongly associated with poor neurocognitive outcomes in adult life [4]. Abacavir has very few real adverse effects but is expensive and may have reduced efficacy in patients with high viral loads, making it less suitable as an initiation drug [5]. Tenofovir is avoided in children owing to concerns about its renal and bone toxicities, which may be more pronounced in growing children than in adults $[6,7]$. In contrast, stavudine is potently effective, cheap and remarkably safe in the short-term (first 6 months of therapy), particularly in settings where routine 
monitoring for acute adverse drug effects is limited. Logistically, the paediatric liquid formulation of stavudine is a dry powder requiring reconstitution with a specific volume (202 $\mathrm{mL}$ ) of distilled water. The resulting liquid must be transported in a cooler box and requires refrigeration at $4{ }^{\circ} \mathrm{C}$ to maintain stability for 1 month. In the rural setting where refrigeration is a rare commodity, the adult formulation is often used in an off-label manner wherein caregivers who do not have access to a refrigerator are instructed to disperse the contents of an adult capsule in $5 \mathrm{~mL}$ of water and then withdraw the required fraction using a syringe. The accuracy and bioavailability of this 'opened capsule' administration method for stavudine have been validated [8]. In contrast to abacavir, the stavudine adult capsule formulation has a well-established supply chain throughout Africa and is stable at room temperature $\left(<25^{\circ} \mathrm{C}\right)$ for at least 2 years. Thus, stavudine remains a commonly used ART drug for children in the developing world.

The frequency and severity of stavudine-related lipoatrophy and dyslipidaemia are strongly dependent on the dose and duration of use. The likelihood of developing this mitochondrial toxicity appears to be directly linked to the intracellular concentration of stavudine's phosphorylated intracellular metabolite, stavudine triphosphate (d4T-TP) [9]. The in vitro $50 \%$ inhibitory concentration $\left(\mathrm{IC}_{50}\right)$ of d4T-TP against HIV-1 is between $0.009 \mu \mathrm{M}$ and $6 \mu \mathrm{M}$, depending on the phenotypic and genotypic resistance to nucleoside reverse transcriptase inhibitors [10]. The d4T-TP concentration required to inhibit half-maximum human mitochondrial DNA polymerase $\gamma$ activity, which is responsible for synthesis of proviral DNA, was ca. $0.05 \mu \mathrm{M}$ [11]. The current standard adult dose of $30 \mathrm{mg}$ b.i.d. achieves a median intracellular d4T-TP concentration in the 
mid range of the $\mathrm{IC}_{50}$ values (ca. $2-3 \mu \mathrm{M}$ ) [12], yet produces an excellent virological response. As a result, several strategies of dose reduction have been hypothesised [12-14].

In 2007, a meta-analysis by Hill et al. showed that a reduced adult dose of either $20 \mathrm{mg}$ or $30 \mathrm{mg}$ b.i.d. significantly lowers the frequency of delayed toxicity (lipoatrophy, dyslipidaemia, lactic acidosis, peripheral neuropathy) while maintaining excellent antiviral efficacy [13]. In response, the World Health Organization (WHO) recommended that the adult dose be reduced to $30 \mathrm{mg}$ b.i.d. [15]. The paediatric dose, however, has not yet been reduced. Up to now, there has been resistance to reducing the paediatric dose, with antagonists citing a lack of evidence showing that antiviral efficacy will be maintained at the lower dose. A substantial reduction in the standard paediatric dose is likely to drastically reduce the frequency and severity of lipoatrophy, dyslipidaemia and insulin resistance, allowing continued safe use of this highly effective, logistically simple, widely available and remarkably cheap ART drug.

\section{Methods}

\subsection{Physiologically-based pharmacokinetic (PBPK) approach}

The approach taken in this study utilises a 'bottom-up' approach that combines physicochemical properties, intrinsic clearance and physiological system information to describe the population of interest with PBPK models [16]. A typical organ compartment depicted in Fig. 1 can be solved mathematically by mass balance on each 
compartment. Assuming perfusion-limited kinetics, Equation 1 is the mass balance equation for a compartment $j$, representing a generic organ, except for the lung.

$$
\frac{V_{\mathrm{tis}} d C_{\mathrm{tis}}}{d t}=Q_{\mathrm{tis}}\left(C_{\mathrm{b}, \mathrm{a}}-\frac{C_{\mathrm{tis}}}{K_{\mathrm{p}} / K_{\mathrm{B}: \mathrm{P}}}\right)-R
$$

where $Q_{\mathrm{tis}}$ is the blood flow for the tissue compartment, $K_{\mathrm{p}}$ is the tissue-to-plasma partition coefficient, $K_{\mathrm{B}: P}$ is the blood-plasma partition coefficient, subscript b represents blood and tis represents tissue, $C_{\text {tis }}$ is the drug concentration in the tissue, $C_{b, a}$ is the drug concentration in the arterial blood and $V_{\text {tis }}$ is the tissue volume. For a noneliminating tissue, $R$ is negligible. For an eliminating tissue, $R$ can be defined by $\mathrm{CL}_{\mathrm{int}, \mathrm{u}}\left(\frac{C_{\mathrm{tis}} \cdot \mathrm{f}_{\mathrm{up}}}{K_{\mathrm{p}}}\right)$, where $\mathrm{CL}_{\mathrm{int}, \mathrm{u}}$ represents the unbound intrinsic clearance of the tissue and $f_{\text {up }}$ represents the fraction unbound in plasma.

Assuming that the lung is not an eliminating organ, the kinetics of the drug in the lung compartment can be described by:

$$
\frac{V_{\mathrm{lu}} d C_{\mathrm{lu}}}{d t}=Q_{\mathrm{lu}}\left(C_{\mathrm{b}, \mathrm{v}}-\frac{C_{\mathrm{lu}}}{K_{\mathrm{p}} / K_{\mathrm{B}: \mathrm{P}}}\right)
$$

where $V_{\mathrm{lu}}, Q_{\mathrm{lu}}$ and $C_{\mathrm{lu}}$ are the volume, blood flow and drug concentrations in the lung, and $C_{\mathrm{b}, \mathrm{v}}$ represents the drug concentration in venous blood.

The mass balance equation for the venous blood is as follows: 


$$
\frac{V_{\mathrm{b}, \mathrm{v}} d C_{\mathrm{b}, \mathrm{v}}}{d t}=\sum_{i} Q_{t, i}\left(\frac{C_{t, i}}{K_{\mathrm{p}} / K_{\mathrm{B}: \mathrm{P}}}\right)-Q_{\mathrm{lu}} C_{\mathrm{b}, \mathrm{v}}
$$

where $i$ represents the various organs that are connected to the venous blood compartment except the lung, and $V_{b, v}$ is the volume of the venous blood.

For the arterial blood, the kinetics is defined by:

$$
\frac{V_{\mathrm{b}, \mathrm{a}} d C_{\mathrm{b}, \mathrm{a}}}{d t}=Q_{\mathrm{lu}}\left(\frac{C_{\mathrm{lu}}}{K_{\mathrm{p}} / K_{\mathrm{B}: \mathrm{P}}}-C_{\mathrm{b}, \mathrm{a}}\right)
$$

where $V_{\mathrm{b}, \mathrm{a}}$ is the volume of the arterial blood.

\subsection{Model development and qualification}

The PBPK model for stavudine utilises a perfusion-limited clearance consisting of 13 compartments representing various organs, as shown in Fig. 2, in the full advanced dissolution, absorption and metabolism (ADAM) PBPK model in Simcyp v. 14 (Simcyp Ltd., Sheffield, UK). The physicochemical properties of stavudine were obtained from publicly available information and the pharmacokinetic parameters from published scientific literature, as listed in Table 1. The full PBPK model uses the predicted volume of distribution values for stavudine, which was based on the method by Rodgers and Rowland [17]. 
The resulting exposure parameter, the area under the concentration-time curve (AUC), was compared with the literature values from in vivo studies [8,18-21]. The model qualification was measured by the slope $(\beta)$ of the regression line:

$$
\text { predicted } \mathrm{AUC}_{0-\infty}=\alpha+\beta\left(\text { observed } \mathrm{AUC}_{0-\infty}\right)+\varepsilon
$$

The intercept $(\alpha)$ was set to 0 . The error term $(\varepsilon)$ was used to account for interstudy variation. The PBPK model of stavudine redistribution and elimination in adults is qualified if the two-sided $90 \%$ confidence interval $(\mathrm{Cl})$ of the slope of the regression line for the predicted mean $\mathrm{AUC}_{0-\infty}$ lies within 0.8 and 1.25 of the literature-reported geometric mean $\mathrm{AUC}_{0-\infty}$ at various doses.

The formulation was assumed to be a solution as the drug is often administered using the open-capsule method to paediatric patients in rural sub-Saharan Africa. Simulations were conducted in virtual populations of HIV-infected patients who were assumed to not deviate significantly in physiological parameters from those in healthy subjects, contained in the Simcyp population library. The age groups for the simulations are listed in Table 2, with 500 simulated individual profiles per age group. Using the current standard weight-band paediatric dosing, the real dose ranged from $0.61 \mathrm{mg} / \mathrm{kg}$ to 1.50 $\mathrm{mg} / \mathrm{kg}$ b.i.d. for children under 9 years with body weight $<30 \mathrm{~kg}$. Jullien et al. have previously shown that the weight-band dosing chart for antiretroviral drugs in children results in a mean actual stavudine dose of $1.23 \pm 0.47 \mathrm{mg} / \mathrm{kg}$ across all weight ranges 
for infants and children older than 2 weeks and weighing up to $30 \mathrm{~kg}$ [22]. The simulation for body weight $\geq 30 \mathrm{~kg}$ assumed a dose of $30 \mathrm{mg}$ b.i.d. Qualification of the paediatric PBPK model was based on whether the $95 \%$ prediction intervals of the simulated profiles captured the majority of the paediatric data from Jullien et al. [22].

\subsection{Relating intracellular $d 4 T$-TP concentrations to mitochondrial toxicity}

Formation of intracellular d4T-TP was previously described as a rapid event [12]. This phenomenon was assumed in the simulations. The mass balance equation to describe the kinetics of intracellular d4T-TP was described by first-order accumulation and decay [12]:

$$
\frac{V_{\text {cell }} d[\mathrm{~d} 4 \mathrm{~T}-\mathrm{TP}]}{d t}=V_{\text {cell }}\left(\mathrm{K}_{\mathrm{PP}} \cdot C_{\mathrm{p}}-\mathrm{K}_{\mathrm{DP}} \cdot \mathrm{d} 4 \mathrm{~T}-\mathrm{TP}\right)
$$

where $V_{\text {cell }}$ represents the volume of the cell with a value of $0.32 \mathrm{pL}$ [12], and $\mathrm{K}_{\mathrm{PP}}$ and $\mathrm{K}_{\mathrm{DP}}$ are the accumulation and decay rate constants set to $1.45 \mathrm{~h}^{-1}$ and $0.526 \mathrm{~h}^{-1}$, respectively. $C_{p}$ refers to the plasma stavudine concentration.

The intracellular concentrations of d4T-TP were simulated according to Equation 6 and the mean intracellular d4T-TP concentrations were obtained by integrating the concentration-time curve and dividing the total area under the curve by the last time point of the simulated concentrations. 


\subsection{Simulations of the physiologically-based pharmacokinetic model}

The pharmacokinetic simulations were conducted according to the population characteristics listed in Table 2. The 500 simulations of 30,40 and $70 \mathrm{mg}$ b.i.d. in a virtual adult population were compared with literature that reported stavudine exposure with these three doses $[8,18-21]$. The paediatric simulations consisted of $0.61 \mathrm{mg} / \mathrm{kg}$ b.i.d. in neonates up to 2 weeks of age, $1.23 \mathrm{mg} / \mathrm{kg}$ b.i.d. in children 2 weeks to 9 years and $31.5 \mathrm{mg}$ b.i.d. in adolescents aged $9-18$ years. Based on the growth chart from the US Centers for Disease Control and Prevention (CDC), the majority of children under the age of 9 years have a body weight $<30 \mathrm{~kg}$ [23]. For this reason, 9 years of age was chosen as the cut-off value to differentiate those with weight $<30 \mathrm{~kg}$ versus those $\geq 30$ $\mathrm{kg}$.

The reduced adult dose used in the simulation was $20 \mathrm{mg}$ b.i.d. and the resulting steady-state mean intracellular triphosphate metabolite concentration was compared with that in the paediatric population administered the reduced dose of $0.5 \mathrm{mg} / \mathrm{kg}$ b.i.d. between the age of 2 weeks and 9 years. The male and female populations for all virtual populations were assumed to be equal in proportion.

The simulation of intracellular d4T-TP was performed using NONMEM v.7.2 and NMTRAN pre-processor (ICON Development Solutions, Ellicott City, MD). The subroutine was Advan9. The statistical evaluation of the simulated profiles was accomplished in $\mathrm{R}$ version 3.0. 


\section{Results}

\subsection{Physiologically-based pharmacokinetic model development}

The simulated concentration-time profiles at doses of $30-70 \mathrm{mg}$ b.i.d. in adults, 0.61 $\mathrm{mg} / \mathrm{kg}$ in newborn to 13 days old, $1.23 \mathrm{mg} / \mathrm{kg}$ in children between 2 weeks to 9 years and $31.5 \mathrm{mg}$ in children 9-18 years were compared with the literature values as shown in Figs 3 and 4. There was an adequate agreement between the PBPK-predicted $\mathrm{AUC}_{0-}$ ${ }_{\infty}$ and the mean $\mathrm{AUC}_{0-\infty}$ from the literature. The slope of the regression line was 1.11 with a $90 \% \mathrm{Cl}$ of $0.99-1.23$. The intercept was assumed to be 0 , given that one would not expect to have any observable exposure when drug is not administered. The PBPK model assumed linear dose proportionality. The majority of the predicted and published mean AUCs were within the $0.8-1.25$ slope of the line of unity, except for the higher dose of $70 \mathrm{mg}$. This is likely due to non-dose proportionality. Dose proportionality was previously observed between the $5 \mathrm{mg}$ and $40 \mathrm{mg}$ capsule [18]. This non-proportionality in the $70 \mathrm{mg}$ does not affect our simulations as we investigated doses of $20 \mathrm{mg}$ and 40 mg in adults.

In the paediatric population, the dosing regimens were more variable, ranging from 0.61 $\mathrm{mg} / \mathrm{kg}$ b.i.d. in neonates to $1.50 \mathrm{mg} / \mathrm{kg}$ b.i.d. in children with body weight $<30 \mathrm{~kg}$, with a mean of $1.23 \mathrm{mg} / \mathrm{kg}$ b.i.d.; and $31.5 \mathrm{mg}$ b.i.d. in adolescents with body weight $\geq 30 \mathrm{~kg}$ [22]. We therefore used the doses from Jullien et al. [22] for validation purposes. We plotted the $95 \%$ prediction interval of the simulated data set over the observed stavudine exposure in children reported by Jullien et al. [22], since no AUCs in paediatrics were computed in their original article. As shown in Fig. 4, the prediction 
interval of the simulated data sets represented by the shaded area encompassed the majority of observed paediatric stavudine concentration-time profiles, indicating that the scaling from the adult to the paediatric population using the PBPK approach was reasonable and can be used to simulate intracellular levels of d4T-TP using the current standard dose and the proposed reduced dose.

\subsection{Simulation of reduced dose in children}

The rationale for using a solution formulation in the paediatric simulation is that the method of administration for paediatric dosing in sub-Saharan Africa often employs the open-capsule method, which allows adjusting paediatric doses by body weight [8]. The capsule content is dispersed in $5 \mathrm{~mL}$ of water. The measured dose by volume is drawn up using a syringe and is administered orally. The absorption profile from this method is similar to that of a solution.

The in vivo levels of phosphorylated stavudine in the lymphocyte peripheral blood mononuclear cells were simulated using the parameter values from Hurwitz and Schinazi [12], for Equation 6. The simulated plasma concentration of stavudine from the PBPK model was represented by $C_{p}$ in the same equation. The key modelling assumption was that the formation of intracellular phosphorylated stavudine was rapid and equilibrium was reached instantly. Qualification of the simulation was performed by plotting the model-simulated steady-state intracellular d4T-TP median and 95\% prediction interval in adults receiving $40 \mathrm{mg}$ b.i.d. dose against the data points from Becher et al. [24], wherein the dose was $40 \mathrm{mg}$ b.i.d. for adults weighing $\geq 60 \mathrm{~kg}$ and 30 
mg b.i.d. for adults weighing $<60 \mathrm{~kg}$ (Fig. 5). The resulting mean intracellular levels of the phosphorylated metabolite from the simulation closely matched the observed levels from Domingo et al. [9]. Fig. 6 shows the boxplots of the simulated steady-state mean intracellular d4T-TP concentrations in seven virtual populations and dosing regimens. For the reduced dosing, the dosing regimen and virtual populations were as follows: (i) $0.5 \mathrm{mg} / \mathrm{kg}$ b.i.d. in children weighing $<30 \mathrm{~kg}$ but older than 2 weeks of age; and (ii) 20 $\mathrm{mg}$ b.i.d. in adults weighing $\geq 30 \mathrm{~kg}$. The simulations based on the conventional dosing regimens were: (i) $1.23 \mathrm{mg} / \mathrm{kg}$ b.i.d. in children weighing $<30 \mathrm{~kg}$ but older than 2 weeks of age; (ii) $1.0 \mathrm{mg} / \mathrm{kg}$ b.i.d. in children weighing $<30 \mathrm{~kg}$ but older than 2 weeks of age; (iii) $0.61 \mathrm{mg} / \mathrm{kg}$ b.i.d. in neonates less than 2 weeks of age; (iv) $31.5 \mathrm{mg}$ b.i.d. in adolescents weighing $\geq 30 \mathrm{~kg}$; and (v) $40 \mathrm{mg}$ b.i.d. in adults with body weight $\geq 60 \mathrm{~kg}$.

In the reduced dose group, the mean steady-state intracellular d4T-TP levels were ca. $11.5 \pm 3.7 \mathrm{fmol} / 10^{6}$ cells and $13.2 \pm 5.4 \mathrm{fmol} / 10^{6}$ cells in the adult and paediatric populations, respectively. In contrast, the non-reduced dosing regimens resulted in approximately double those levels (Table 3). In the standard dose group, the intracellular d4T-TP levels in children 2 weeks to 9 years of age were $27.9 \pm 11.1$ $\mathrm{fmol} / 10^{6}$ cells and $23.7 \pm 7.9 \mathrm{fmol} / 10^{6}$ cells for the $1.23 \mathrm{mg} / \mathrm{kg}$ and $1.0 \mathrm{mg} / \mathrm{kg}$ dosing, respectively. These levels were $25 \%$ and $7 \%$ higher, respectively, than the levels in adults on $40 \mathrm{mg}$ b.i.d. regimens $\left(22.0 \pm 8.6 \mathrm{fmol} / 10^{6} \mathrm{cells}\right)$. Levels in adolescents $<30 \mathrm{~kg}$ were $23.7 \pm 10.1 \mathrm{fmol} / 10^{6}$ cells. 


\section{Discussion}

Clinical studies of a reduced dose of stavudine in children may potentially be hampered by ethical considerations including doubts about the efficacy of half-dose stavudine in children. Prior to carrying out clinical studies evaluating intracellular d4T-TP pharmacokinetics in the paediatric population, simulations utilising a PBPK approach give a reliable prediction of drug redistribution and elimination in this population. The PBPK modelling approach provides a unique ability to integrate organ maturation information into the simulation model for various age groups [25].

Our simulation suggests that the current standard paediatric weight-band dosing may lead to intracellular d4T-TP concentrations $7-25 \%$ higher than that of the original adult dose of $40 \mathrm{mg}$ b.i.d., which is known to be associated with a wide range of dosedependent toxicities [9] and was reduced globally in 2007 to $30 \mathrm{mg}$ b.i.d. owing to significant unnecessary dose-related toxicity [13]. The paediatric dose, however, has not yet been reduced and our data suggest that the current standard paediatric dose may place children at even higher risk of these conditions than adults exposed to $40 \mathrm{mg}$ b.i.d.. By contrast, our simulation suggests that the d4T-TP concentrations achieved by a dose of $0.5 \mathrm{mg} / \mathrm{kg}$ b.i.d. in children are marginally higher than those achieved by an adult dose of $20 \mathrm{mg}$ b.i.d., which has previously been shown to have excellent antiretroviral efficacy [13].

A previous study of 33 adults by Domingo et al. found that the median (interquartile range) steady-state concentration of d4T-TP in patients with lipoatrophy was 20.6 
(14.9-26.9) fmol/ $10^{6}$ cells compared with $13.85(8.6-20.1) \mathrm{fmol} / 10^{6}$ cells in those without lipoatrophy [9]. Our simulation using the proposed $0.5 \mathrm{mg} / \mathrm{kg}$ b.i.d. dose in children resulted in similar values to their non-lipoatrophy-affected (lower dose) group with an mean steady-state level of $13.2 \mathrm{fmol} / 10^{6}$ cells $\left(90 \% \mathrm{Cl} 12.7-13.7 \mathrm{fmol} / 10^{6}\right.$ cells $)$. In their study, all patients in the non-lipoatrophy-affected (lower dose) group had a viral load below $1.28 \log _{10}$ copies $/ \mathrm{mL}$, suggesting that the efficacy of the lower dose was maintained.

Historically, the earliest effective antiretroviral drugs were fast-tracked to reach the very large number of patients in desperate need of effective ART. As a result, many antiretroviral drugs may not have completed the usual rigorous dose optimisation evaluations prior to marketing and distribution [26], which are necessary to minimise dose-dependent toxicities. Drug toxicities are a common cause of inadequate ART adherence. Compared with other medically treated conditions, HIV is unforgiving of poor adherence: drug resistance develops rapidly due to prolific replication combined with a high error rate during transcription of the HIV virus genome, allowing the virus to adapt rapidly to drug pressure. Dose optimisation to minimise toxicities while maintaining antiretroviral efficacy is essential to the success of ART rollout programmes, particularly in the developing world where alternative drug options are limited and drug resistance may spell death [26]. In line with this, the 2011 WHO and UNAIDS treatment 2.0 strategy document for HIV lays out five priority work areas, of which the first is to optimise the dosing of antiretroviral regimens available in low- to middle-income countries with the aim of minimising toxicities while retaining antiretroviral efficacy [27]. 
The current study furthers this aim by demonstrating the likely efficacy and lack of toxicity produced by reducing the current standard paediatric stavudine dose by half.

The extrapolation to paediatric exposure from adult information using PBPK modelling resulted in a closer approximation of stavudine plasma exposure than allometry. We have previously used allometric scaling based on body weight and age to extrapolate adult pharmacokinetic findings to children using data from an adult pharmacokinetic study of stavudine bioavailability with the 'opened capsule' dosing method $[8,14]$. While the interindividual variability in that adult model was relatively small and consequently resulted in tighter simulated paediatric exposure profiles, the comparison with previously published paediatric data was not ideal as the previous allometric scaling model used pharmacokinetic data from a homogeneous adult population [14]. The PBPK-based approach used in the current study better captured not only the true variability in the paediatric population presented by Jullien et al. [22] but also the shape of the distribution and elimination phases. In addition to providing a more accurate simulation of the $0.5 \mathrm{mg} / \mathrm{kg}$ b.i.d. dose in children, the current study demonstrates the advantage of a PBPK model for scaling from adults to children in pharmacokinetic modelling simulations. Cella et al. discussed in great detail the current paradigm for paediatric dose selection and listed reasons why the pharmacokinetics in children may be different from adults, including variability due to age, body composition, enzyme maturation, liver and kidney functionalities [28]. In allometric scaling, which relies primarily on body weight, the dose adjustments are based on the assumption of linearity between body size and drug exposure. There are physiological processes associated with 
developmental growth that may not be accounted for. For this reason, Cella et al. cautioned against such a simplified approach for paediatric clinical research and recommended an integrated model-based pharmacokinetic and pharmacodynamic analysis such as the PBPK modelling approach [28]. From our experience, extrapolation using allometric scaling often shifts the time of peak concentration later, especially in lower age groups [29], whereas the PBPK approach retains the shape of the concentration-time profiles.

In addition, the allometric scaling approach relies heavily on the generalisability of data in an original data set, an inherent weakness when extrapolating to a subpopulation not well represented in the original data set. In contrast, the PBPK approach incorporates known differences in drug disposition between adults and children [30]. The combination of in vitro-in vivo extrapolation and PBPK techniques enabled us to build a more accurate 'virtual' paediatric population [31] with reduced reliance on the original data set, facilitating a more accurate prediction of drug absorption, distribution, metabolism and excretion in children. Using the PBPK approach, the current study predicted pharmacokinetic parameter distributions $\left(V_{s s} / F\right.$ and $\left.C L / F\right)$ consistent with published values for stavudine [18]. In addition, our PBPK model was extended to include biochemical modelling aspects and the pharmacodynamic aspect of the simulation resulted in data comparable with the available data in the literature [9].

In a later study, Domingo et al. showed that a thymidylate synthetase genetic polymorphism was associated with d4T-TP intracellular levels [32]. Among the low- 
expressing thymidylate synthetase genotypes, those that were associated with higher propensity for toxicity had higher intracellular d4T-TP levels, similar to those found in adults taking $40 \mathrm{mg}$ b.i.d. [32]. The same polymorphism has also been associated with peripheral neuropathy in patients on stavudine-based therapy [33]. The current study did not evaluate the effect of polymorphism in thymidylate synthetase on intracellular d4T-TP accumulation as there is a lack of in vitro studies to characterise the kinetics of thymidylate synthetase in the various genotypes.

In conclusion, a large proportion of paediatric patients may be overdosed at the current standard paediatric dose, resulting in intracellular exposures far above that needed to inhibit viral replication. The current standard paediatric stavudine dose may result in even higher mean intracellular d4T-TP concentrations than the original adult dose of 40 mg b.i.d., placing children at markedly higher risk of metabolic toxicities than adults on the reduced dose of $30 \mathrm{mg}$ b.i.d.. A reduction of the paediatric dose to $0.5 \mathrm{mg} / \mathrm{kg}$ b.i.d. would provide intracellular d4T-TP levels similar to the $20 \mathrm{mg}$ b.i.d. adult dose, which has been shown to have potent antiretroviral efficacy yet markedly reduced toxicity, allowing continued safe use of this highly effective, logistically simple, widely available and remarkably cheap ART drug.

Funding: SI received support through a Fogarty International Clinical Research Fellowship grant [\#R24-TW007988-01], a pilot research grant [\#P30 Al036214-16, subaward \#10304442] from the University of California San Diego Centre for AIDS Research (UCSD CFAR), a Southern Africa Consortium for Research Excellence 
(SACORE) sub-grant [\#WTX055734] from the Wellcome Trust, a research grant [\#158Inn] from the Collaborative Initiative for Paediatric HIV Education and Research (CIPHER), a research grant [OPP1065257] from the Bill \& Melinda Gates Foundation, and a research grant [COL116446] from the GSK/ViiV Foundation. MFC received grants from the National Institutes of Health [\#R01-Al 076199, 5R01HD069169-02, R01HD071664], from the National Institute of Allergy and Infectious Diseases (NIAID) through the International Maternal Pediatric Adolescent AIDS Clinical Trials Group (IMPAACT) [\#5U01AI069521-01 to 04] and through the Comprehensive International Plan for Research in AIDS (CIPRA-SA) [\#1U19AI53217-01], from Social \& Scientific Systems, Inc. through IMPAACT [BRS-IMPCT-S-11-000331-001458, BRS-IMPCT-S11-000331-001552], from USAID [\#674-A-00-09-00001-00] and from the US Centers for Disease Control and Prevention [\#2009-N-11094]. The recruits on this study were not co-enrolled in any IMPAACT trial.

Competing interests: None declared.

Ethical approval: Not required. 


\section{References}

[1] Innes S, Cotton MF, Haubrich R, Conradie MM, van Niekerk M, Edson C, et al. High prevalence of lipoatrophy in pre-pubertal South African children on antiretroviral therapy: a cross-sectional study. BMC Pediatr 2012;12:183.

[2] Alam N, Cortina-Borja M, Goetghebuer T, Marczynska M, Vigano A, Thorne C, et al.; European Paediatric HIV and Lipodystrophy Study Group in EuroCoord. Body fat abnormality in HIV-infected children and adolescents living in Europe: prevalence and risk factors. J Acquir Immune Defic Syndr 2012;59:314-24.

[3] Giuliano IDB, de Freitas SFI, de Souza M, Caramelli B. Subclinic atherosclerosis and cardiovascular risk factors in HIV-infected children: PERI study. Coron Artery Dis $2008 ; 19: 167-72$.

[4] Walker SP, Wachs TD, Gardner JM, Lozoff B, Wasserman GA, Pollitt E, et al. Child development: risk factors for adverse outcomes in developing countries. Lancet 2007;369:145-57.

[5] Technau KG, Lazarus E, Kuhn L, Abrams EJ, Sorour G, Strehlau R, et al. Poor early virologic performance and durability of abacavir-based first-line regimens for HIV-infected children. Pediatr Infect Dis J 2013;32:851-5.

[6] Soler-Palacín P, Melendo S, Noguera-Julian A, Fortuny C, Navarro ML, Mellado MJ, et al. Prospective study of renal function in HIV-infected pediatric patients receiving tenofovir-containing HAART regimens. AIDS 2011;25:171-6.

[7] Bunders MJ, Frinking O, Scherpbier HJ, van Arnhem LA, van Eck-Smit BL, Kuijpers TW, et al. Bone mineral density increases in HIV-infected children 
treated with long-term combination antiretroviral therapy. Clin Infect Dis 2013;56:583-6.

[8] Innes S, Norman J, Smith P, Smuts M, Capparelli E, Rosenkranz B, et al. Bioequivalence of dispersed stavudine: opened versus closed capsule dosing. Antivir Ther 2011;16:1131-4.

[9] Domingo P, Cabeza MC, Pruvost A, Salazar J, Gutierrez Mdel M, Mateo MG, et al. Relationship between HIV/highly active antiretroviral therapy (HAART)associated lipodystrophy syndrome and stavudine-triphosphate intracellular levels in patients with stavudine-based antiretroviral regimens. Clin Infect Dis 2010;50:1033-40.

[10] Calvez V, Costagliola D, Descamps D, Yvon A, Collin G, Cécile A, et al. Impact of stavudine phenotype and thymidine analogues mutations on viral response to stavudine plus lamivudine in ALTIS 2 ANRS trial. Antivir Ther 2002;7:211-8.

[11] Lim SE, Copeland WC. Differential incorporation and removal of antiviral deoxynucleotides by human DNA polymerase $\gamma$. J Biol Chem 2001;276:2361623.

[12] Hurwitz SJ, Schinazi RF. In silico study supports the efficacy of a reduced dose regimen for stavudine. Antivir Res 2011;92:372-7.

[13] Hill A, Ruxrungtham K, Hanvanich M, Katlama C, Wolf E, Soriano V, et al. Systematic review of clinical trials evaluating low doses of stavudine as part of antiretroviral treatment. Expert Opin Pharmacother 2007;8:679-88. 
[14] Sy SK, Innes S, Derendorf H, Cotton MF, Rosenkranz B. Estimation of intracellular concentration of stavudine triphosphate in HIV-infected children given a reduced dose of 0.5 milligrams per kilogram twice daily. Antimicrob Agents Chemother 2014;58:1084-91.

[15] World Health Organization. Addendum to 2006 WHO guidelines on antiretroviral therapy for HIV infection in adults and adolescents. Geneva, Switzerland: WHO; 2007.

[16] Sy SK, Wang X, Derendorf H. Introduction to pharmacometrics and quantitative pharmacology with an emphasis on physiologically based pharmacokinetics. In: Schmidt S, Derendorf H, editors. Applied pharmacometrics. 1st ed. Springer; 2014. p. 1-64.

[17] Rodgers T, Rowland M. Mechanistic approaches to volume of distribution predictions: understanding the processes. Pharm Res 2007;24:918-33.

[18] Kaul S, Mummaneni V, Barbhaiya $\mathrm{RH}$. Dose proportionality of stavudine in HIV seropositive asymptomatic subjects: application to bioequivalence assessment of various capsule formulations. Biopharm Drug Dispos 1995;16:125-36.

[19] Narang VS, Lulla A, Malhotra G, Purandare S. Bioequivalence evaluation of two marketed brands of stavudine $40 \mathrm{mg}$ capsules in healthy human South African volunteers. Pharmacol Res 2004;50:511-6.

[20] Rainey PM, Friedland G, McCance-Katz EF, Andrews L, Mitchell SM, Charles $\mathrm{C}$, et al. Interaction of methadone with didanosine and stavudine. J Acquir Immune Defic Syndr 2000;24:241-8. 
[21] Kaul S, Christofalo B, Raymond RH, Stewart MB, Macleod CM. Effect of food on the bioavailability of stavudine in subjects with human immunodeficiency virus infection. Antimicrob Agents Chemother 1998;42:2295-8.

[22] Jullien V, Rais A, Urien S, Dimet J, Delaugerre C, Bouillon-Pichault M, et al. Age-related differences in the pharmacokinetics of stavudine in 272 children from birth to 16 years: a population analysis. Br J Clin Pharmacol 2007;64:105-9. [23] Kuczmarski RJ, Ogden CL, Guo SS, Grummer-Strawn LM, Flegal KM, Mei Z, et al. 2000 CDC growth charts for the United States: methods and development. Vital Health Stat 11 2002;(246):1-190.

[24] Becher F, Landman R, Mboup S, Kane CN, Canestri A, Liegeois F, et al. Monitoring of didanosine and stavudine intracellular trisphosphorylated anabolite concentrations in HIV-infected patients. AIDS 2004;18:181-7.

[25] Barrett JS, Della Casa Alberighi O, Laer S, Meibohm B. Physiologically based pharmacokinetic (PBPK) modeling in children. Clin Pharmacol Ther 2012;92:40-9.

[26] Vento S, Lanzafame M, Lattuada E, Cainelli F, Restelli U, Foglia E. Dose reduction of antiretrovirals: a feasible and testable approach to expand HIV treatment in developing countries. Trop Med Int Health 2013;18:40-4.

[27] World Health Organization. The treatment 2.0 framework for action: catalysing the next phase of treatment, care and support. Geneva, Switzerland: WHO; 2011.

[28] Cella M, Knibbe C, Danhof M, Della Pasqua O. What is the right dose for children? Br J Clin Pharmacol 2010;70:597-603. 
[29] Sy SK, Asin-Prieto E, Derendorf H, Samara E. Predicting pediatric agematched weight and body mass index. AAPS J 2014;16:1372-9.

[30] Rostami-Hodjegan A, Tucker GT. Simulation and prediction of in vivo drug metabolism in human populations from in vitro data. Nat Rev Drug Discov $2007 ; 6: 140-8$.

[31] Rostami-Hodjegan A. Physiologically based pharmacokinetics joined with in vitro-in vivo extrapolation of ADME: a marriage under the arch of systems pharmacology. Clin Pharmacol Ther 2012;92:50-61.

[32] Domingo P, Cabeza MC, Pruvost A, Torres F, Salazar J, del Mar

Gutierrez M, et al. Association of thymidylate synthase gene polymorphisms with stavudine triphosphate intracellular levels and lipodystrophy. Antimicrob Agents Chemother 2011;55:1428-35.

[33] Domingo P, Cabeza Mdel C, Torres F, Salazar J, Gutierrez Mdel M, Mateo MG, et al. Association of thymidylate synthase polymorphisms with acute pancreatitis and/or peripheral neuropathy in HIV-infected patients on stavudinebased therapy. PLoS One 2013;8:e57347. 
Fig. 1. A representative organ of the body, representing blood flow and tissue perfusion. $V_{\mathrm{b}}$, volume of blood; $C_{\mathrm{b}, \mathrm{a}}$, drug concentration in the arterial blood; $V_{\mathrm{tis}}$, tissue volume; $C_{\text {tis }}$, drug concentration in the tissue; $K_{\mathrm{P}}$, tissue-to-plasma partition coefficient; $R$, elimination process; $Q_{\mathrm{tis}}$, blood flow for the tissue compartment.

Fig. 2. Schematic representation of the physiologically-based pharmacokinetic model to simulate stavudine redistribution and elimination in adults and children.

Fig. 3. Correlation between physiologically-based pharmacokinetic-predicted adult exposures, measured by the geometric mean of the area under the concentration-time curve from 0 to infinity $\left(\mathrm{AUC}_{0-\mathrm{inf}}\right)$, and literature-reported $A \cup \mathrm{C}_{0-\text { inf }}$ in adults. The solid line represents the line of unity and the dotted lines represent lines with slope 0.8 and 1.25. The dashed line represents the best fit for the regression.

Fig. 4. Accuracy of the physiologically-based pharmacokinetic model evaluated by overlaying the median and $95 \%$ prediction interval in individuals receiving twice-daily stavudine at a dose of: $0.61 \mathrm{mg} / \mathrm{kg}$ in 0-13-day-old infants (dashed line, red shade); $1.23 \mathrm{mg} / \mathrm{kg}$ in children 2 weeks to 9 years of age with $<30 \mathrm{~kg}$ body weight; and $31.5 \mathrm{mg}$ in adolescents 9-18 years of age with body weight $\geq 30 \mathrm{~kg}$ (solid line, blue shade) over the data points from Jullien et al. [22].

Fig. 5. Accuracy of the model-simulated intracellular stavudine triphosphate (d4T-TP) by overlaying the median (solid line) and $95 \%$ prediction interval (grey shaded area) in 
adults receiving $40 \mathrm{mg}$ twice daily (b.i.d.) against the data points from Becher et al. [24]. The doses in Becher et al. were $40 \mathrm{mg}$ b.i.d. for adults weighing $\geq 60 \mathrm{~kg}$ and $30 \mathrm{mg}$ b.i.d. for adults weighing $<60 \mathrm{~kg}$.

Fig. 6. Distribution of simulated steady-state mean intracellular stavudine triphosphate (d4T-TP) concentrations in various virtual paediatric and adult populations receiving the conventional and reduced doses of stavudine. BID, twice daily. 


\section{Table 1}

Summary of stavudine drug-dependent parameters

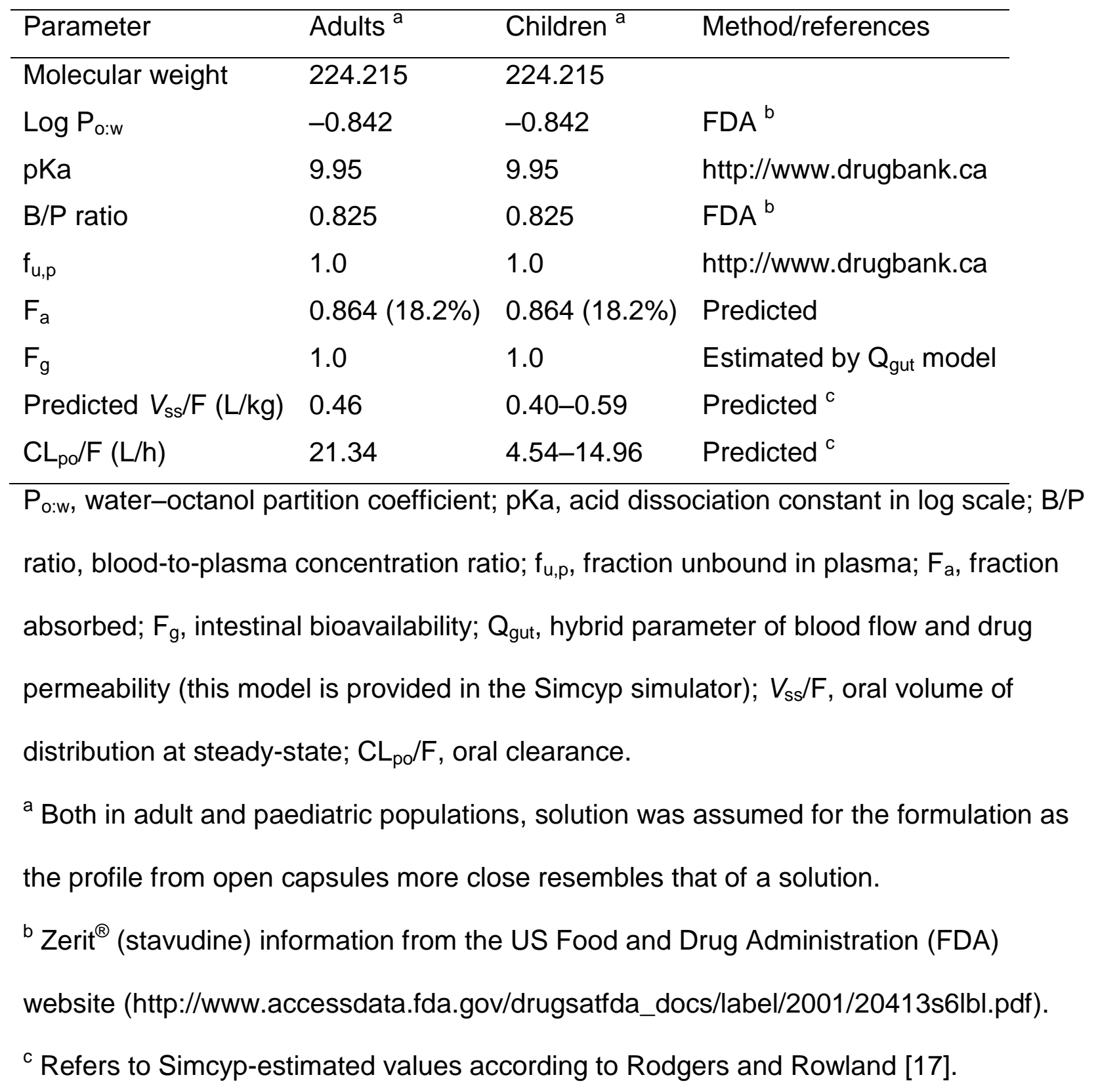




\section{Table 2}

Dosage regimens, age groups and sample size used in simulating stavudine plasma concentration-time profiles using the advanced dissolution, absorption and metabolism (ADAM) physiologically-based pharmacokinetic model

\begin{tabular}{|c|c|c|c|c|c|c|c|}
\hline & \multicolumn{4}{|c|}{ Standard dose } & \multicolumn{3}{|c|}{ Reduced dose } \\
\hline $\begin{array}{l}\text { Virtual } \\
\text { population }\end{array}$ & Adults & Neonates & Paediatric & Paediatric & Adolescent & Paediatric & Adults \\
\hline Sample size & 500 & 500 & 500 & 500 & 500 & 500 & 500 \\
\hline Age & 20-50 years & $0-13$ days & $\begin{array}{c}2 \text { weeks to } 9 \\
\text { years }\end{array}$ & $\begin{array}{c}2 \text { weeks to } 9 \\
\text { years }\end{array}$ & 9-18 years & $2-9$ years & $20-50$ years \\
\hline Ratio (M:F) & $1: 1$ & $1: 1$ & $1: 1$ & $1: 1$ & $1: 1$ & $1: 1$ & $1: 1$ \\
\hline $\begin{array}{l}\text { Dose } \\
\text { regimen }\end{array}$ & $\begin{array}{l}\text { 30/40/70 mg } \\
\text { b.i.d. }\end{array}$ & $\begin{array}{l}0.61 \mathrm{mg} / \mathrm{kg} \\
\text { b.i.d. }\end{array}$ & $\begin{array}{l}1.23 \mathrm{mg} / \mathrm{kg} \\
\text { b.i.d. }\end{array}$ & $\begin{array}{l}1.0 \mathrm{mg} / \mathrm{kg} \\
\text { b.i.d. }\end{array}$ & $\begin{array}{l}31.5 \mathrm{mg} \\
\text { b.i.d. }\end{array}$ & $\begin{array}{l}0.5 \mathrm{mg} / \mathrm{kg} \\
\text { b.i.d. }\end{array}$ & 20 mg b.i.d. \\
\hline Duration & Single dose & Single dose & Single dose & Single dose & Single dose & $\begin{array}{l}\text { Multiple/156 } \\
\text { h }\end{array}$ & $\begin{array}{l}\text { Multiple/156 } \\
\text { h }\end{array}$ \\
\hline
\end{tabular}

M:F, male:female; b.i.d., twice daily. 


\section{Table 3}

Summary of mean steady-state intracellular stavudine triphosphate levels in the virtual populations at conventional and reduced doses

\begin{tabular}{|c|c|c|c|c|c|c|c|}
\hline \multirow[b]{2}{*}{ Virtual population } & \multicolumn{5}{|c|}{ Conventional dose } & \multicolumn{2}{|c|}{ Reduced dose } \\
\hline & Adults & Neonates & Paediatric & Paediatric & Adolescent & Paediatric & Adults \\
\hline Dosing regimen & $\begin{array}{l}40 \mathrm{mg} \\
\text { b.i.d. }\end{array}$ & $\begin{array}{l}0.61 \mathrm{mg} / \mathrm{kg} \\
\text { b.i.d. }\end{array}$ & $\begin{array}{l}1.23 \mathrm{mg} / \mathrm{kg} \\
\text { b.i.d. }\end{array}$ & $\begin{array}{l}1.0 \mathrm{mg} / \mathrm{kg} \\
\text { b.i.d. }\end{array}$ & $\begin{array}{l}31.5 \mathrm{mg} \\
\text { b.i.d. }\end{array}$ & $\begin{array}{l}0.5 \mathrm{mg} / \mathrm{kg} \\
\text { b.i.d. }\end{array}$ & $\begin{array}{l}20 \mathrm{mg} \\
\text { b.i.d. }\end{array}$ \\
\hline $\begin{array}{l}\text { Mean } \pm \text { S.D. } \\
\left(\mathrm{fmol} / 10^{6} \text { cells }\right)\end{array}$ & $\begin{array}{c}22.0 \pm \\
8.6\end{array}$ & $10.1 \pm 4.2$ & $27.9 \pm 11.1$ & $23.7 \pm 7.9$ & $23.7 \pm 10.1$ & $13.2 \pm 5.4$ & $\begin{array}{l}11.5 \pm \\
3.7\end{array}$ \\
\hline $\begin{array}{l}\text { Median (fmol/10 } 6 \\
\text { cells) }\end{array}$ & 21.0 & 9.4 & 26 & 22.6 & 21.5 & 12.4 & 11.0 \\
\hline $\begin{array}{l}90 \% \mathrm{Cl}\left(\mathrm{fmol} / 10^{6}\right. \\
\text { cells) }\end{array}$ & $\begin{array}{r}21.2- \\
22.8\end{array}$ & $9.8-10.5$ & 27.0-28.9 & 23.0-24.4 & $22.8-24.5$ & $12.7-13.7$ & $\begin{array}{r}11.2- \\
11.9\end{array}$ \\
\hline
\end{tabular}

b.i.d., twice daily; S.D., twice daily; $\mathrm{Cl}$, confidence interval. 


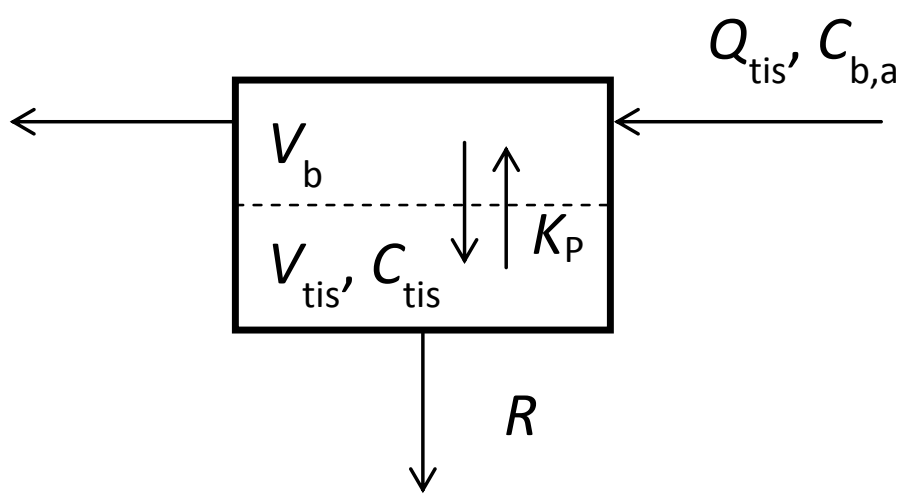




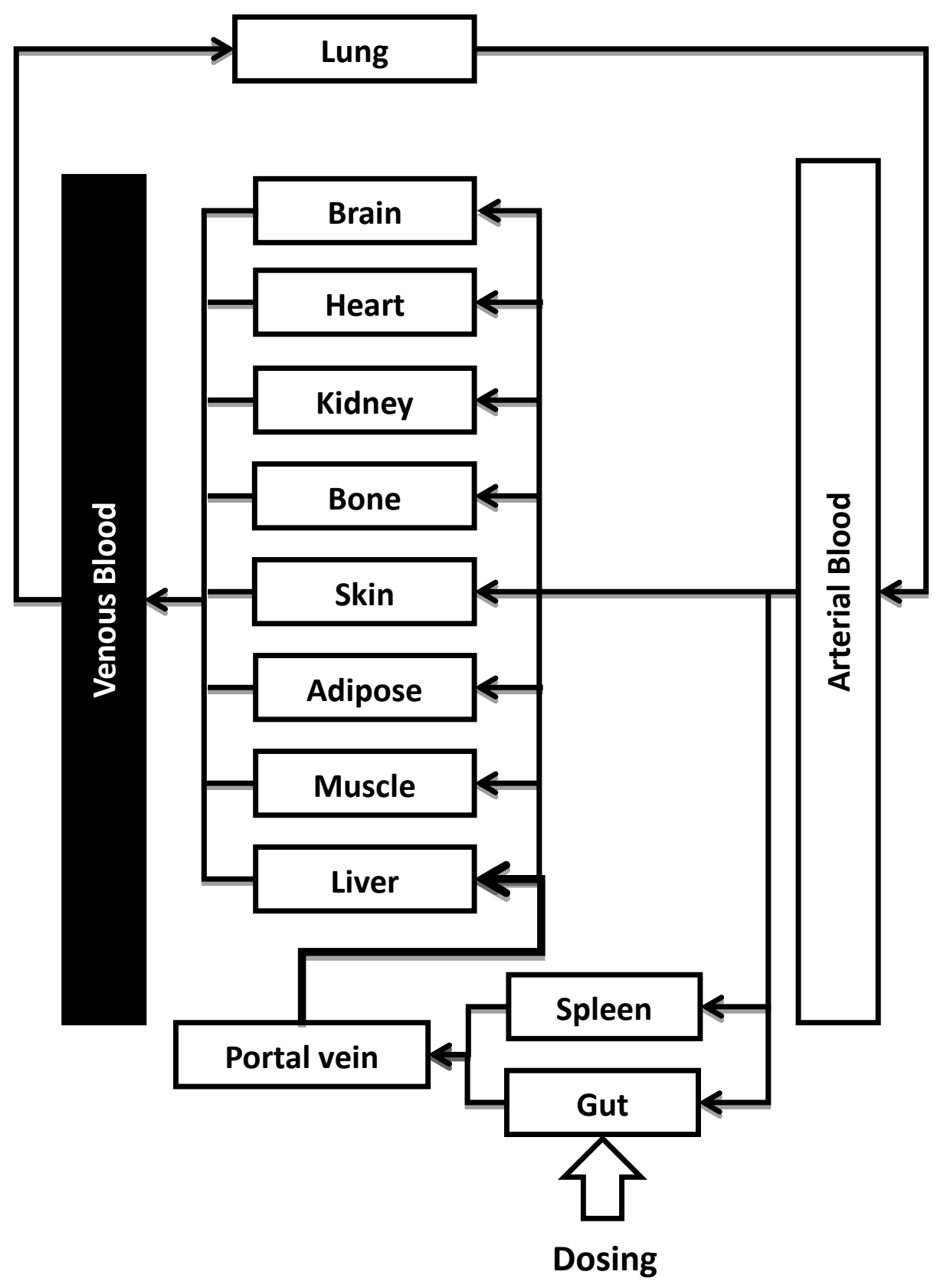




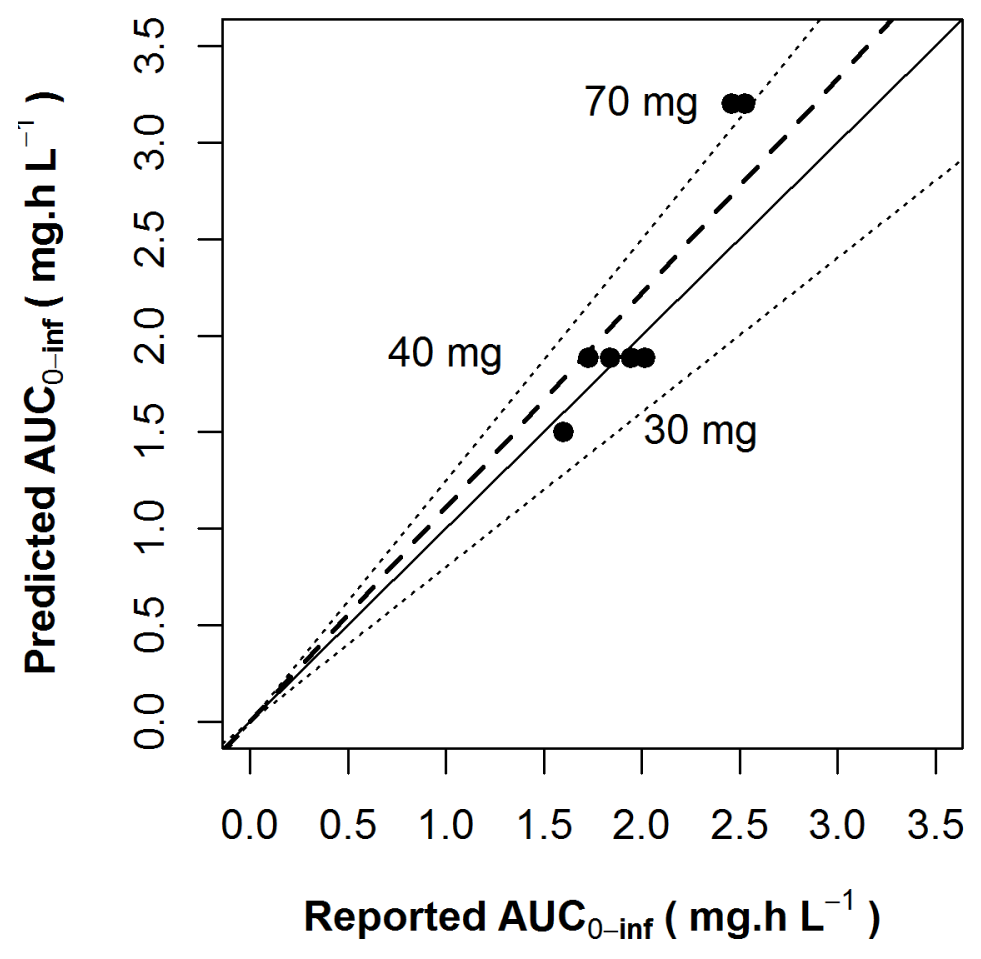




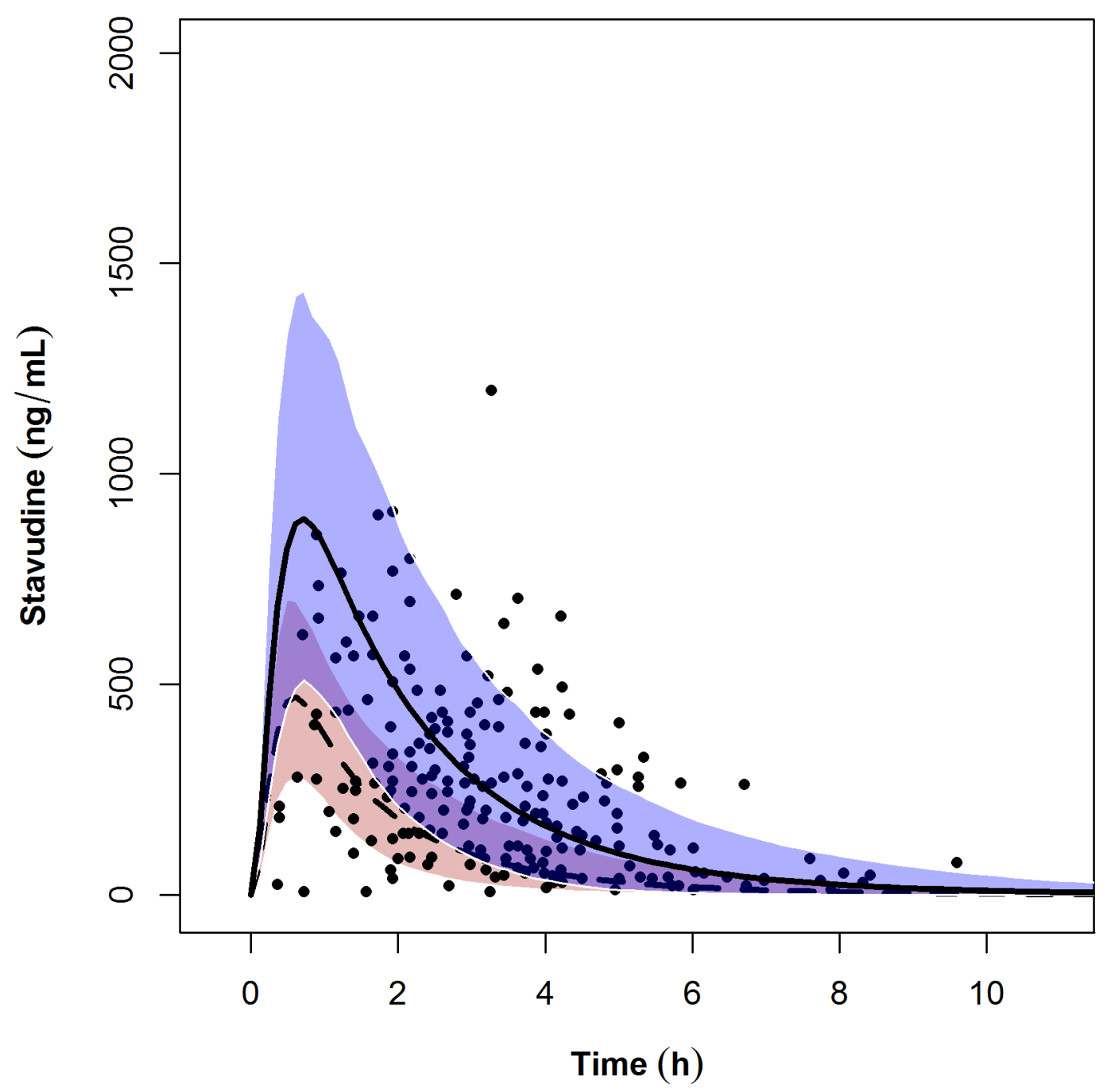




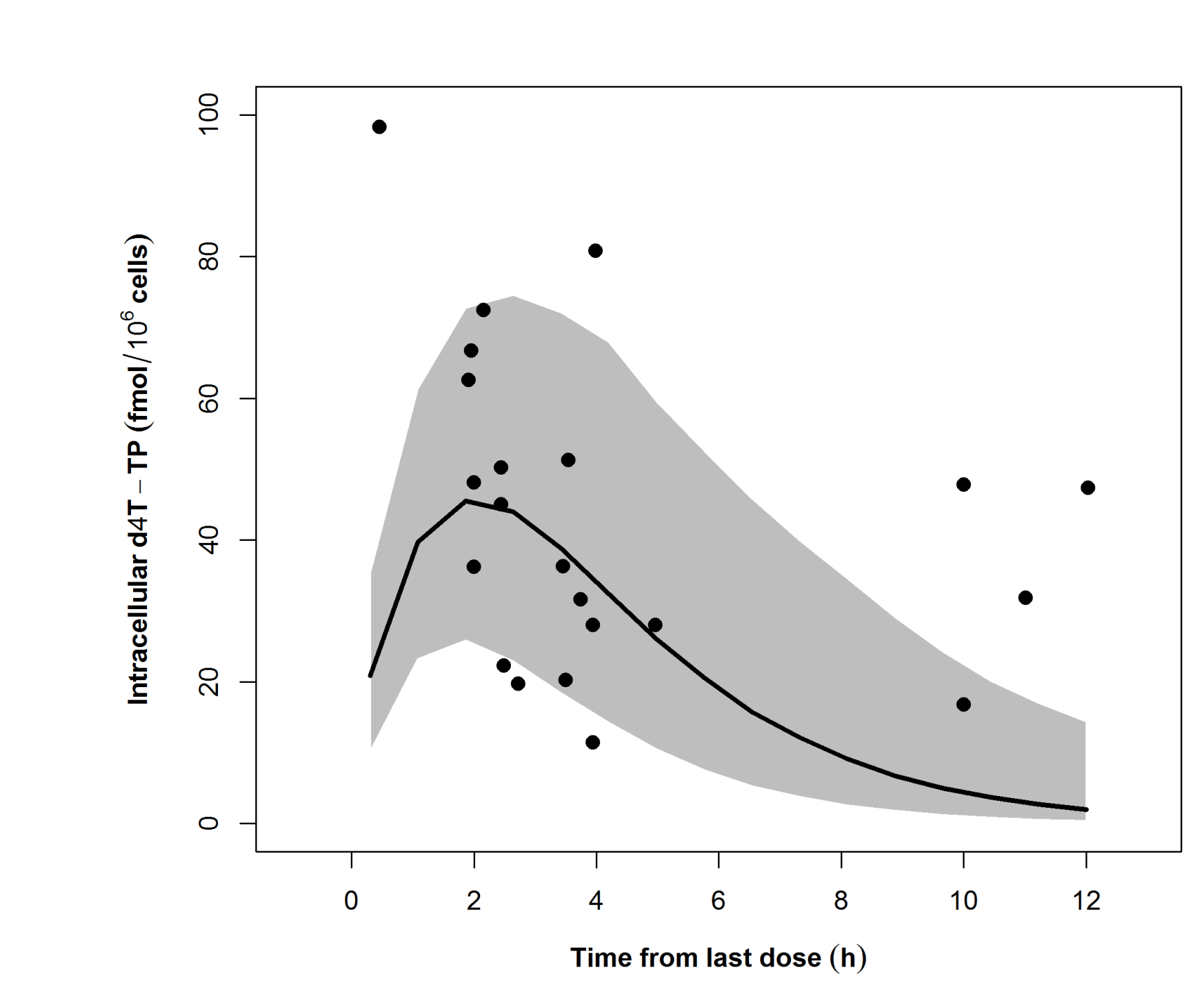

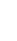

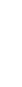

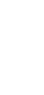

Edited Figure 5
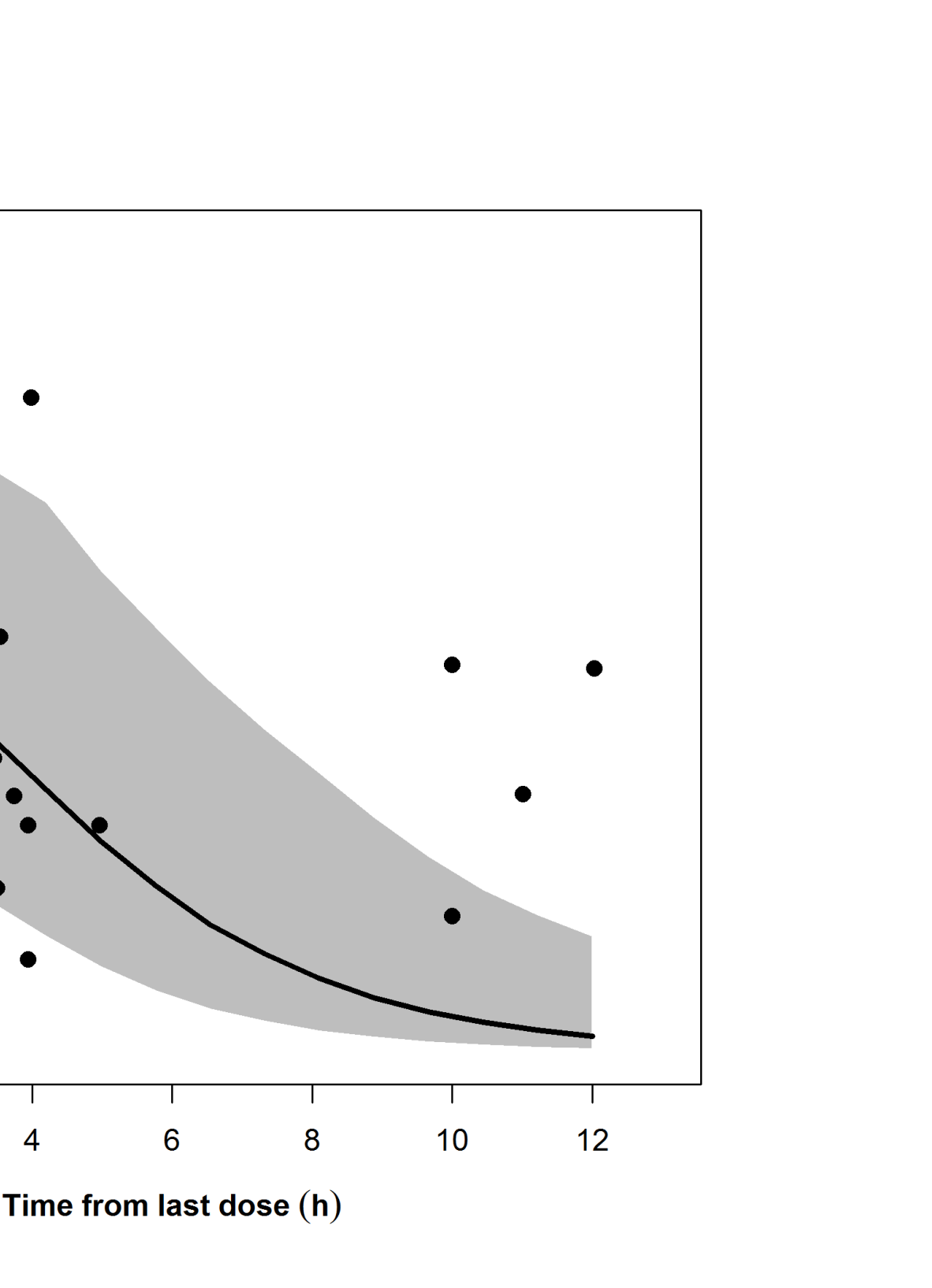


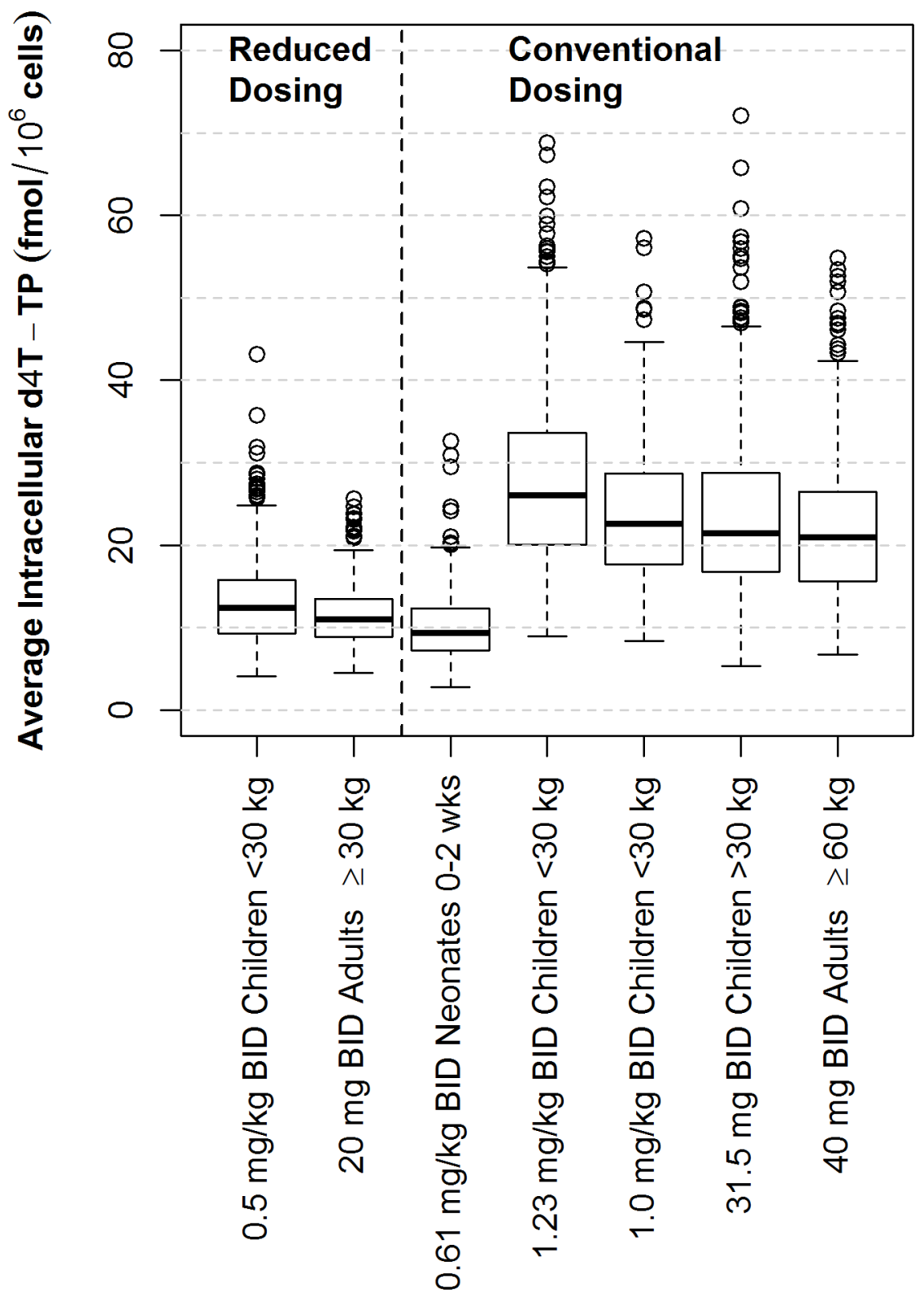

